\title{
Malignant degeneration of cystic teratoma of the ovary: two cases report
}

\author{
Asma Hmila*, Hafsa Taheri, Hanane Saadi, Ahmed Mimouni
}

Department of Obstetrics and Gynecology, University Hospital Mohammed VI, Oujda, Morocco

Received: 03 February 2020

Accepted: 29 February 2020

\section{*Correspondence:}

Dr. Asma Hmila,

E-mail: hmila_asma.tn@outlook.com

Copyright: (C) the author(s), publisher and licensee Medip Academy. This is an open-access article distributed under the terms of the Creative Commons Attribution Non-Commercial License, which permits unrestricted non-commercial use, distribution, and reproduction in any medium, provided the original work is properly cited.

\begin{abstract}
The malignant degeneration of mature ovarian teratomas is a rare phenomenon. Case reported two cases of squamous cell carcinoma developed on mature teratoma of the ovary in patients aged 54 and 41 who were seen for chronic pelvic pain. Their pelvic ultrasound showed cystic double-component images with sizes of 103 and $95 \mathrm{~mm}$ respectively suggestive of dermoid cysts, and the anatomopathological study of the pieces of adnexectomy confirmed the diagnosis. Although no clinical, radiological or biological signs are specific, ovarian dermal cyst degeneration is suspected in the presence of a large dermoid cyst in a postmenopausal or peri-menopausal woman. The careful anatomo-pathological study of the cyst in this case makes it possible to pose the diagnosis of certainty. A rare complication of the dermoid cyst, its prognosis is pejorative and depends mainly on its clinical stage at the time of diagnosis and the quality of its surgical treatment which must be as radical as possible.
\end{abstract}

Keywords: Ovary, Prognosis, Squamous cell carcinoma, Teratome, Treatment

\section{INTRODUCTION}

Worldwide, long acting reversible contraceptives mature ovarian teratomas or dermoid cysts are the most common non-epithelial tumors of the ovary. They can be of ectodermal (skin, nerve tissue), mesodermal (muscle, adipose tissue) or endodermal origin (digestive tissue, bronchi). Rarely, these tumors are complicated by malignant degeneration (1 to $3 \%$ of cases) often in the peri-menopause. ${ }^{1}$ Their preoperative diagnosis is difficult because of the absence of clinical or radiological signs of specificity and their therapeutic protocol is not yet well codified. This case report two cases of squamous cell carcinoma developed on mature cystic teratomas of the ovary.

\section{CASE REPORT}

Clinical case no 1: This is a 54-year-old multiparous, menopausal patient with no significant pathological history who suffers from chronic pelvic pain. Pelvic ultrasonography showed the presence of a 103/63 mm Doppler vascularized triple-component posterior and leftuterine image suggestive of a dermoid ovarian cyst (Figure 1).

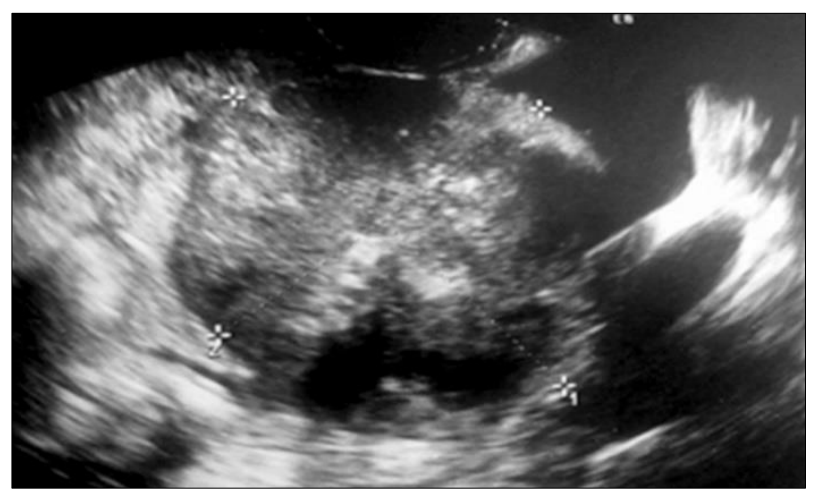

Figure 1: Ultrasound aspect of the ovarian cyst. 




Figure 2: MRI aspect of the ovarian cyst.

Pelvic MRI (Figure 2) revealed a left laterouterin solidocystic mass of $80 / 73 \mathrm{~mm}$, suggesting a malignant process most probably related to a serous cystadenocarcinoma of the ovary. The patient underwent laparoscopy with the discovery of a thick-walled left ovary cyst adhering to the ipsilateral fallopian tube and the gastrointestinal tract (Figure 3).

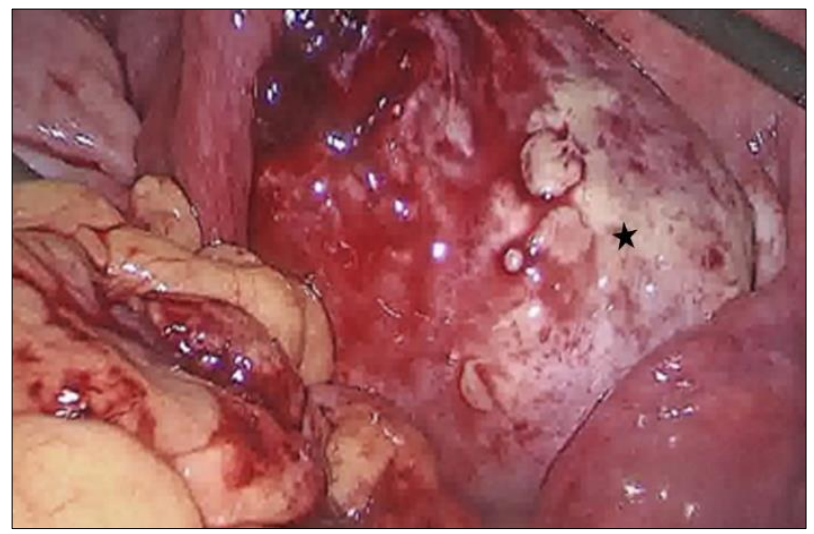

Figure 3: Laparoscopic appearance of the carcinogenic dermoid cyst.

Case proceeded to a left adnexectomy. His anatomopathological examination came back in favour of a mature teratoma partially infiltrated by a well differentiated and keratinizing squamous cell carcinoma of the left ovary; the capsule was intact. The tumor extension assessment was normal. The tumor markers, in particular CA-125, CA-19.9, ACE, AFP, CA-125, BHCG and LDH are normal.

Complementary management was performed by total hysterectomy, right adnexectomy, omentectomy and bilateral iliac lymphadenectomy, whose pathological examination was free from tumor infiltration.

Clinical case no 2: This is a 41-year-old multiparous patient with no significant pathological history who consulted for chronic pelvic pain. Pelvic ultrasound revealed a solido-cystic laterouterine mass of $95 \mathrm{~mm}$. CA-125 was negative. Thoraco-abdominopelvic CT showed the cyst without evidence of peritoneal carcinomatosis (Figures 4, 5).



Figure 4: CT appearance of the ovarian cyst in transversal section.

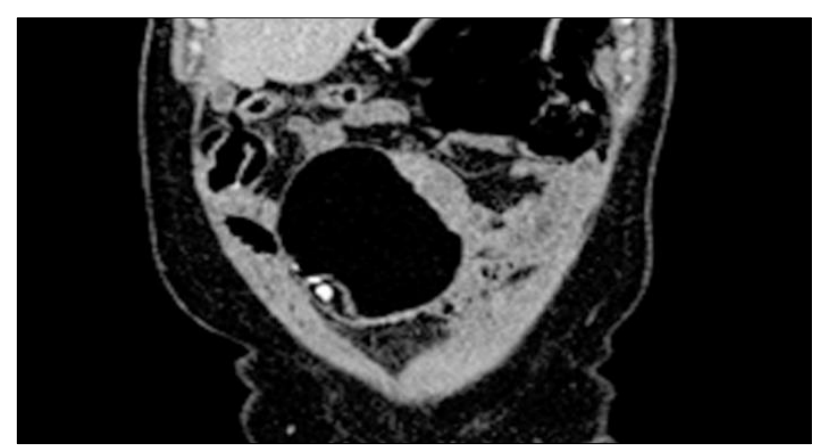

Figure 5: CT appearance of the ovarian cyst in frontal section.

The patient first benefited from a right adnexectomy with peritoneal cytology by laparoscopy whose anatomopathological results came back in favour of welldifferentiated keratinizing squamous cell carcinoma developed on a mature dermoid cyst of the right ovary with negative peritoneal cytology. Authors then completed a total hysterectomy with left adnexectomy, omentectomy and bilateral ilio-obturator dissection. The tumor was classified pTlapN0pMx. No adjuvant treatment has been prescribed. The evolution was marked by an evolutionary resumption of the tumor six months later in the form of peritoneal carcinosis and the patient was put under chemotherapy.

\section{DISCUSSION}

Mature teratomas are the most common germ cell tumors $(10-20 \%){ }^{1}$ Their malignant degeneration is a known phenomenon although occurring only in $1-3 \%$ of the cases. $^{2}$ It is most often in the form of squamous cell carcinoma because of the greater involvement of tissue of ectodermal origin in these teratomas. It can also be adenocarcinoma, melanoma or sarcoma. ${ }^{3}$

Although mature ovarian teratomas are often seen in young women, their cancerization occurs preferentially in 
menopausal or peri-menopausal women with an average age of 54 years, as is the case with the case patients. ${ }^{1,4}$

The radiological diagnosis of the dermoid cyst is quite easy, but malignant degeneration is difficult to predict. However, it is evoked behind the advanced age of the woman (55 years against 37.5 years for benign mature teratoma), the size of the tumor (on average $152 \mathrm{~mm}$ against 88 for benign teratomas), the presence of an important tissue component inside the cyst and the existence of an extension towards the neighboring organs. ${ }^{5-7}$

Regarding tumor markers, only the analysis of squamous cell carcinoma antigen (SCC associated antigen) has shown interest in the preoperative detection of malignant transformation of ovarian dermoid cysts and early detection of recurrence. ${ }^{2}$ In the presence of a dermoid cyst, a rate of SCC $\geq 2 \mathrm{ng} / \mathrm{ml}$ makes us search for other elements in favor of malignancy in order to adapt the surgical treatment. ${ }^{8}$

The diagnosis of certainty can only be made on the anatomo-pathological examination of the surgical specimen, hence the importance of extensive sampling in order to detect any foci of even limited malignant degeneration. No therapeutic protocol is clearly established in front of this rare pathology. There is a tendency to be conservative in front of young patients desiring a pregnancy, and more radical in front of a menopausal woman, with a surgery including at least a total hysterectomy with bilateral adnexectomy and omentectomy. The lymphadenectomy is controversial as the extension is done gradually and peritoneally. However, it should be used in patients with macroscopic iliac or lombo-aortic lymphadenopathy.

The use of adjuvant treatments is not yet well codified. He had not shown a real interest in stage Ia tumor. It should be used if it has been rated Ic stage or higher. The latest studies have shown a slight benefit with pelvic irradiation associated with concomitant weekly chemotherapy with cisplatin. ${ }^{9}$

The prognosis for this condition is poor and depends on the FIGO stage, histological type, tumor grade, capsular intrusion, vascular invasion and the quality of surgical resection. Five-year survival is estimated at $50 \%$ for FIGO stages I and $25 \%$ for stage II tumors and $12 \%$ for stage III tumors. ${ }^{10}$

\section{CONCLUSION}

The cancerization of mature teratomas of the ovary is a rare phenomenon. It is suspected in front of a dermoid cyst in a postmenopausal or peri-menopausal woman with a large double or triple component cyst and often positive rate of SCC. His treatment is surgical, often associated with adjuvant radio chemotherapy.

\section{Funding: No funding sources \\ Conflict of interest: None declared \\ Ethical approval: Not required}

\section{REFERENCES}

1. Wei F, Jiang Z, Yan C. Analysis of 20 mature ovarian cystic teratoma cases in postmenopausal women. Chin Med J Eng. 2001;114:137-8.

2. Rim SY, Kim SM, Choi HS. Malignant transformation of ovarian mature cysticteratoma. Int J Gynecol Cancer. 2006;16:140-4.

3. Stamp GW, McConnell EM. Malignancy arising in cystic ovarian teratomas. A report of 24 cases. Br J Obstet Gynaecol. 1983;90:671-5.

4. Guedira I, Znagui R, Boukhanni L, Haqqi L. Tératome cancérisé de l'ovaire. Gynécol Obstét Fertil. 2011:39.

5. Ziyadi M, Hakim I, Guelzim K, Kouach J, Moussaoui D, Dehayni M. Teratome mature cancerise De L'ovaire: A Propos D'un Cas Et Revue De La Litterature. Global J Med Res. 2015;15(3):1-3.

6. Rekhi B, Parikh P, Deodhar KK, Menon S, Maheshwari A, Kerkar R. Squamous carcinoma coexistent with teratoma of ovary: A clinicopathological study of 12 cases diagnosed over a 10 -year period ata tertiary cancer referral center. J Can Res Ther. 2015;11:211-5.

7. Patni R. Squamous cell carcinoma arising in mature cystic teratoma of ovary. J Mid-life Health. 2014;5:10.

8. Kido A, Togashi K, Konishi I, Kataoka ML, Koyama T, Ueda H. Dermoid cysts of the ovary with malignant transformation: MR appearance. AJR Am J Roentgenol. 1999;172:445-9.

9. Karim A, Youbi ZA, Benchakroun N, Jouhadi H, Benider A, Sahraoui S, et al. Cancerization d'un kyste dermoid de l'ovaire : à propose d'un cas. Researchfr. 2015;2:1289.

10. Chiang AJ, La V, Peng J, Yu KJ, Teng NN. Squamous cell carcinoma arising from mature cystic teratoma of the ovary. Int $\mathbf{J}$ Gynecol Cancer. 2011;21:466-74.

Cite this article as: Hmila $\mathrm{A}$, Taheri $\mathrm{H}$, Saadi $\mathrm{H}$, Mimouni A. Malignant degeneration of cystic teratoma of the ovary: two cases report. Int J Reprod Contracept Obstet Gynecol 2020;9:2154-6. 